\title{
Driving Consumer Engagement through Diverse Calls to Action in Corporate Social Responsibility Messages on Social Media
}

\author{
Myoung-Jin Chae (1)
}

check for

updates

Citation: Chae, M.-J. Driving Consumer Engagement through Diverse Calls to Action in Corporate Social Responsibility Messages on Social Media. Sustainability 2021, 13, 3812. https://doi.org/10.3390/ su13073812

\section{Academic Editor:}

Beatriz Aibar-Guzmán and Cristina Aibar-Guzmán

Received: 28 February 2021

Accepted: 28 March 2021

Published: 30 March 2021

Publisher's Note: MDPI stays neutral with regard to jurisdictional claims in published maps and institutional affiliations.

Copyright: (C) 2021 by the author. Licensee MDPI, Basel, Switzerland. This article is an open access article distributed under the terms and conditions of the Creative Commons Attribution (CC BY) license (https:/ / creativecommons.org/licenses/by/ $4.0 /)$.
Department of Marketing and International Business, Lingnan University, 8 Castle Peak Road, Tuen Mun, Hong Kong, China; myoungchae@ln.edu.hk; Tel.: +852-6650-2202

\begin{abstract}
Although a growing number of consumers acknowledge the importance of firms' corporate social responsibility (CSR) activities, how companies can effectively communicate these initiatives to consumers is still a challenge. Although the rise of social media platforms has provided firms with opportunities for more immediate and interactive communication with consumers, recent academic studies related to social media have mostly focused on effective communication of promotional messages, and relatively little attention has been paid to prosocial messages. For better communication, social media branded messages have encouraged user participation (i.e., calls to action), but how diverse types of calls to action can generate consumer engagement remains unexplored. Using over 2000 branded posts from popular consumer product brands on Facebook and Twitter, this research explores diverse types of calls to action that drive consumers' attitudinal (i.e., likes) and behavioral (i.e., shares) engagement with CSR-related messages on social media. The research findings suggest that the types of calls to action matter in the effectiveness of CSR messages. Specifically, CSR messages inviting consumers to brand-related programs or games generated a greater number of likes and shares. However, the overall engagement was lower when CSR messages encouraged further conversations, and rewarding consumers was also less effective. Finally, the results show that multiple calls to action within one message decrease engagement. Overall, this study contributes to the academic literature and management by providing new insights and actionable guidelines on how to encourage user participation when designing CSR messages to enhance consumers' attitudinal and behavioral engagement within social media, thereby contributing to sustainable development while enhancing the effectiveness of marketing communications.
\end{abstract}

Keywords: corporate social responsibility (CSR); social media; sustainable development; consumer engagement; user participation; calls to action

\section{Introduction}

Social media is now essential for companies to promote brands and communicate with consumers due to its interactivity and participatory characteristics [1,2]. Industries and academia have shown its effectiveness on business performance; for example, $80 \%$ of Fortune 500 companies use Facebook for marketing purposes [3], 87\% of small businesses experienced an increase in their profits from these platforms [4], and 85\% of corporate decision makers claimed that use of social media was critical when making business purchases [5].

At the same time, an increasing number of consumers has become more responsive to firms' corporate social responsibility (CSR) involvement [6]. Cone Communications' survey [7] has shown that the percentage of Americans who find it acceptable for companies to be involved in societal issues in their marketing has increased from $66 \%$ in 1993 to $88 \%$, and $90 \%$ of consumers want information from firms regarding how they support social causes. Responding to these growing interests, companies are now involved in creating more CSR-related messages on social media [8] beyond promotional messaging. Promoting causes and societal issues has indeed proven effective on social media platforms. For 
example, Procter \& Gamble (P \& G) launched the Love over Bias campaign to counteract bias and discrimination affecting numerous people. After a story about LGBT rights was showcased in a television show during the campaign, a wave of testimonials appeared on Twitter, through which people shared their own experiences with similar racial, gender, or class bias, using the hashtag \#LoveOverBias. This resulted in 300 million video views, more than five billion of earned-media impressions [9].

Although social media benefits companies because it provides opportunities to promote CSR-related causes, resulting in positive outcomes such as awareness of the issues, consumer participation, enhanced corporate image, and even financial performance [10,11], few studies have further explored ways to utilize social media platforms to better communicate with consumers regarding CSR issues. Although the current CSR literature discusses an overall effectiveness of CSR messages on social media [12,13], the types of messaging in terms of content characteristics, formats, topics, and tones must be further explored.

In this research, we would like to focus on calls to action (i.e., firm-initiated participation embedded in social media messages to encourage user participation and engagement; [14]) in order to explore ways to promote CSR messages. Calls to action are the most popular and actionable practice in social media adopted by practitioners and described in the literature due to the interactive nature of the platform [15]. Additionally, studies have shown that encouraging participation is particularly critical in social media because it enhances consumer experience through participation [16], making them "active co-producers" who participate in firm-initiated activities, express their views, and interact with other users [17].

Based on these motivations, this research investigates how to design CSR messages using calls to action to enhance engagement in social media. This study aims to answer the following questions: (1) What types of calls to action on social media drive consumer engagement? More specifically, how do such diverse types of calls to action lead to consumers' attitudinal and behavioral engagement outcomes? (2) Does using more calls to action within CSR messages generate greater engagement?

For analysis, data were collected from official accounts created by popular consumer product brands on Facebook and Twitter to test the theoretical framework. Since there is little evidence of different types of calls to action in the literature, this study is exploratory in nature and categorizes types of calls to action based on the data and examples of branded messages and investigates how they become more or less effective for CSR messages. In so doing, this research is among the first in the literature to examine the types of calls to action to enhance the effectiveness of CSR messages on social media, and it contributes to the field by advancing the knowledge of how to be more effective, beyond whether these calls are effective.

We argue that considering calls to action as a means to promote CSR messages will provide actionable and clear guidelines to companies because this practice seeks more specific outcomes by requesting directly the types of contributions they expect from consumers and receives immediate and visible outcomes by assessing the level of attitudinal and behavioral engagement in those messages. In addition, calls to action in CSR messages in social media lead to sustainable development goals (SDGs) through consumers' active and direct participation in diverse activities because they encourage the actual behavior, not limited to awareness. Moreover, companies can benefit from enhanced attitudinal and behavioral engagement in social media messages, followed by enhanced firm performance and marketing capabilities. Therefore, our research discusses a "win-win" scenario for companies' business performance and long-term development in society.

The remaining parts of the paper are as follows. First, it describes what is known about CSR communications on social media and the effects of user participation in social media in literature before developing the conceptual framework and hypotheses. Second, it discusses the data and empirical considerations along with how these concerns are addressed, followed by empirical findings and discussions. Finally, it presents managerial 
implications based on the findings and suggests future research directions founded on the study limitations.

\section{Conceptual Framework and Hypotheses}

\subsection{Corporate Social Responsibility and Social Media}

Extant social media literature has mostly focused on the effects of content characteristics in promotional messages on consumer attitudinal and behavioral outcomes [3,18-21], while more attention needs to be paid to societal messages [22,23] because social media serves as a platform where several major social movements, such as \#MeToo movement, start and go viral [24]. Understanding the nature of the platform and societal issues provides firms an opportunity to enhance marketing strategies and communications [24]. Understanding the gap in the literature, recent studies have argued that firms must more actively utilize social media platforms because they provide a channel for consumers to learn more about CSR activities and share their thoughts [25].

Studies have shown the overall effectiveness of social media platforms in promoting CSR issues and enhancing consumer engagement in the messages [12,13,26,27]. Du and Vieira [28] have suggested that CSR communications through social media help reduce consumers' skepticism toward CSR activities. In addition, Lee, Dolen, and Kolk [29] have found that social media helps generate consumer awareness of CSR issues because users can easily share their views without companies' intervention. This study argues that promotion of CSR issues on social media is critical because successful CSR actions and communications can lead to diverse beneficial outcomes such as consumers' positive word of mouth, willingness to pay a premium, and resilience to companies' negative news [10], which extend to financial performance [11] and improved corporate image [30].

Beyond the overall effectiveness of CSR messaging on social media, researchers have studied how to communicate CSR issues to consumers. Uzunoğlu, Turkel, and Akyar [2] have examined types of CSR and found that CSR messages must be economical and ethical at the same time to increase purchase intention. According to Wang and Huang [31], internal CSR messages (i.e., messages about improving employee benefits within an organization) are more effective than external messages (i.e., messages about contributing to society) in improving trust and commitment toward the organization. Moreover, Sreejesh, Sarkar, and Sarkar [32] have shown that CSR messages should contain society-serving rather than self-serving motives to enhance consumer-brand relationships.

Although these studies suggest novel ways to communicate CSR on social media better, the perspective of two-way interaction has not been fully examined [33]. Zizka [33] has argued that companies have focused on providing information to consumers in a oneway direction, and the aspects of two-way interaction should be further explored on social media. Given the real-time, fast, and interactive nature of social media platforms [15,34], more studies are needed on how two-way interactions facilitate and encourage consumers participation in and contribution to CSR messaging.

\subsection{Firm-Initiated Participation on Social Media}

The literature has closely examined user participation and/or co-creation in online platforms due to their positive impacts and outcomes. For example, user participation and value co-creation in online platforms lead to greater consumer loyalty $[35,36]$ and willingness to pay for premium options [37]. The mechanisms whereby user participation increases these outcomes can be explained in several ways. First, users must justify the effort they put into the contents and therefore appreciate them more [38]. Second, people are generally happier when making an effort rather than remaining idle (i.e., idleness aversion [39]). These mechanisms apply even when the efforts are made mandatorily [14].

Although the above findings focus on efforts that are voluntarily made by users, one of the prominent features of social media is that it can directly and explicitly encourage users' immediate participation and contribution beyond simply providing information or waiting for users to contribute in some way. As a means to encourage contribution, calls 
to action are a form of firm-initiated participation defined as "graphic or textual prompts that require users' immediate attention and response" [14]. This practice has been broadly used in the Internet context as a form of website-issued prompts, not limited to social media, and is known to affect subsequent perceptions and behaviors [40]. An experiment by Drenner et al. [41] shows that requesting users to tag photos on the website has led to an increase in voluntary tagging behaviors and subsequent participation in other activities on the website. Moreover, companies use diverse forms of calls to action on their websites by asking consumers to like or share the content, follow the link, watch a video, add the account to favorites, vote, and read more information in order to capture their attention and encourage specific types of contributions they wish to achieve. When these actions are requested, users' donations and participation generally increase [14] and advertising recognition is enhanced [42], compared to when the actions are not explicitly requested. Furthermore, in a study by Zalmanson, Oestreicher-Singer, and Perez [43], when prompted to rate their experience with calls to action, users were more likely to convert to a paid version of services.

Similarly, calls to action have been defined among practitioners as "a statement designed to get an immediate response from the person reading or hearing it" [44]. In the social media context, it specifically refers to "a way for firms to entice social media audience to focus their attention on the next action the firms want them to take" [45]. Industry reports have also shown that the average amount of interaction increased after calls to action were introduced on Facebook [46]. In summary, definitions by and discussions among both scholars and practitioners show that the key aspects of calls to action in the social media context include "explicitly" asking for the types of participation or contribution to their social media messages and encourage users to "voluntarily" engage in the content. Noting the positive outcomes of calls to action, practitioners have been actively discussing how to utilize such practice on social media platforms [47].

However, the literature has also examined concerns and negative effects related to calls to action. Handayani et al. [48] have suggested that calls to action increase consumers' impulsive purchasing and decrease their perceived enjoyment of the content. Similarly, Edwards et al. [49] have shown that calls to action decrease user satisfaction and overall enjoyment of the website experience as they often feel forced to contribute to the content while consuming it. In addition, consumers also have privacy concerns and do not always trust the website because they are often required to reveal personal information [40].

Overall, these study findings have mainly focused on the overall effectiveness of calls to action on consumer outcomes, and the impacts are both positive and negative. However, few studies have further investigated factors such as content characteristics, formats, and topics of calls to action to enhance their effectiveness. Thus, this research argues that more studies are necessary to gain a better understanding of what causes calls to action to be effective and how to utilize diverse types of calls to action to enhance consumer engagement.

\subsection{Types of Calls to Action}

Although researchers have examined whether calls to action drive participation in and engagement with message content, few studies have further investigated different types of calls to action in terms of content characteristics, formats, or topics. For example, Chen, Yeh, and Chang [42] have studied a specific call to action, a shop-now function, in advertising effectiveness, but the research is limited to one type of call to action that is specific to online advertising rather than social media. Since there were not sufficient grounds from the literature to build a theoretical framework, the model in this study is mainly driven by data and examples that have been adopted in practice, whereas evidence from previous studies related to this research context was considered as supporting arguments.

Companies use diverse tools on social media platforms to explicitly request specific actions that they want their consumers to take (e.g., asking consumers to like or share the post, leave comments, watch videos, follow links in the posts, read and learn more about 
the issues, participate in events, vote, etc.). Using one or a combination of these items as a tool, companies attempt to achieve specific contributions to or participation in the content from consumers.

Since the established framework regarding the types of contributions is still at an early stage in the literature, our classification of calls to action started with an exploratory analysis, adapting the grounded theory approach [50]. First, we analyzed the dataset and identified five common types of contributions that companies solicit from users, making sure that they were collectively exhaustive. Next, we coded the posts in our dataset into the five categories using an online panel with detailed instructions and examples to show how to code the posts according to the five categories. For validation, we found evidence in the literature on some of our categories and their effectiveness. In addition, we found industry examples and ensured that the types of calls to action classified in our research have also been used in practice.

Along with the five types of calls to action developed in our study, we found evidence in the related literature to support our theoretical framework. Firstly, the mechanisms through which each call to action enhances or decreases CSR communication effectiveness are based on literature regarding consumers' perceptions of CSR motives. A large body of the literature on CSR suggests that consumers favor CSR activities perceived to serve society while being skeptical and less amenable toward CSR activities perceived to serve the self (i.e., the company's own profits; [32,51]). Such perceived motives of CSR activities are determined by various factors including consumers' co-creation [32] or interest in the issues [52].

In particular, evidence from the literature suggests that consumers' perceived benefits and/or the efforts that firms put into the message are drivers of attitudes toward the message and consumer skepticism [53-55]. This is based on the equity theory by Adams [56], which contends that an individual considers personal benefits compared to personal efforts, in addition to the other's benefits compared to efforts, and perceptions of inequity arise when the balance of these benefit-to-effort ratios is broken. In the context of marketing communications, consumer perceptions of greater personal investments (i.e., efforts) and/or firm benefits lead to inferences that the firm's persuasion methods are inappropriate or unfair, while they form more favorable attitudes toward the message when greater consumer benefits and/or firm efforts are perceived [53]. Therefore, we predict that calls to action in CSR messages that require greater consumer efforts while showing fewer firm efforts are perceived as unfair or less sincere and thereby lead to consumer skepticism toward the CSR messages. On the other hand, when calls to action in CSR messages show greater firm efforts and greater consumer benefits, they will be perceived as more sincere in serving society and thereby lead to higher levels of consumer engagement.

Secondly, we considered the entertainment aspect of branded posts as an important driver of engagement in social media $[57,58]$ and posit that calls to action in CSR messages will be more engaging when they are entertaining.

\subsubsection{Invitation to Brand Programs}

Social media is considered an effective platform on which to promote a company's own programs or events because it can encourage consumers to participate directly and immediately. Companies also promote socially responsible marketing campaigns or programs to support causes and enhance consumer engagement in these issues. For example, the Save Our Species campaign promoted by Lacoste on Facebook was intended to protect nature and wildlife and received mainstream media coverage [9]. We predict that promoting these types of programs or campaigns increases perceived firms' efforts in the message because it showcases that companies are putting a great amount of effort into supporting relevant causes, thus leading to the perception that their motives are sincere $[53,54]$ and that they have society-serving motives rather than self-interests. Furthermore, encouraging consumers to contribute to specific programs that are directly relevant to the company leads to a greater fit between the company's CSR activities and its business [52], enhancing 
positive attitudes toward the company. This is in line with the findings in the literature on the fit between brand personality and sponsoring events, which results in positive attitudes toward the brand [59]. Therefore, it is predicted that invitations to programs or campaigns supported or promoted by companies (i.e., brand programs) have a positive impact on engagement with CSR messages.

Hypothesis 1 (H1). Invitations to brand programs will increase consumer engagement in social media when used in CSR messages.

\subsubsection{Invitation to External Events}

Similar to brand programs, many companies also use external events as an opportunity to induce interest and encourage participation in branded messages as communication on social media is fast and in real time [34]. For example, companies make use of external events or news (e.g., sporting events such as the Olympic Games or presidential election) as an opportunity to capture consumers' attention and encourage participation in their messages. Similar to inviting consumers to brand programs, we predict that engaging consumers in specific forms of external events also shows firms' efforts and indicates that they are sincerely serving society $[53,54]$. In addition, by companies participating in events that are of great interest to the public, consumers will perceive greater benefits from these messages. This study also posits that linking branded posts to external events that are popular among consumers will garner greater attention and interest, leading to higher engagement based on the entertaining aspects [57,58]. Based on these reasons, invitations to participate in external events are seen to have a positive impact on engagement with CSR messages due to the perception of society-serving motives.

Hypothesis 2 (H2). Invitations to external events will increase consumer engagement with social media when used in CSR messages.

\subsubsection{Invitation to Games}

Beyond promotions of programs or events, companies often use various types of fun activities on social media to capture consumers' attention by being interactive and in real time. Scholars have shown that marketing in the format of games increases brand engagement through its highly interactive and optimally challenging characteristics, resulting in a closer connection with the brand [60]. The format of these types of games in social media is diverse, including competitions, questions asking consumers to provide free-format answers or choose the correct answer, or encouragement of consumers to connect with others (e.g., Corona's invitation to a contest at the Corona SunSets, which is a worldwide beach festival). These mainly entertaining game characteristics are often effective in generating interest, capturing greater attention, and encouraging participation if they are used in CSR messages $[48,57,58]$. Moreover, we predict that consumers perceive benefit from participating in these activities because they are able to enjoy the content and perceive firms' efforts required to create the activities. Therefore, invitations to games are likely to be perceived as having sincere motives to serve society rather than the firms, leading to a positive impact on engagement $[53,54]$.

Hypothesis 3 (H3). Invitations to games will increase consumer engagement with social media when used in CSR messages.

\subsubsection{Invitation to Storytelling}

Rather than a specific form of events or programs, companies also invite consumers to storytelling by encouraging them to have further conversations about various topics. For example, companies ask consumers to provide their experiences with products or services to determine any possible revisions to be made in the future. They also ask consumers to share their thoughts and feedback on new products. In addition, some firms encourage consumers to provide comments about or support for social issues to promote 
CSR messages. For instance, a posting by Dove asked consumers to share their experiences with and thoughts about women in their family to encourage conversations and support women. Although these types of practices have been actively adopted by many brands, it is plausible that invitations to storytelling are less likely to attract consumers because they are less entertaining and less specific in terms of goals compared to the other forms of calls to action, leading to lower levels of engagement [57,58]. Moreover, since creating a message that includes an invitation to storytelling does not require as much effort as other forms of messages, consumers may perceive that companies are expending less effort but gaining greater benefits while asking for more contributions to the content from the consumer side, resulting in skepticism toward companies' ability to deliver effective messages [61]. Based on the previous literature [53,54], we predict that the greater effort by consumers and less effort by firms perceived in these practices will lead to the perception that firms are less sincere about serving society and are attempting to serve themselves instead. Therefore, it is likely to be perceived that companies have self-serving motives with invitations to storytelling.

Hypothesis 4 (H4). Invitations to storytelling will decrease consumer engagement with social media when used in CSR messages.

\subsubsection{Rewarding Consumers}

Companies encourage consumers' contributions to their content by promising rewards for participation. These rewards take various forms such as information (i.e., learning from posts), appreciation, amusing or emotional experiences, and monetary compensation. For example, a social media post by the Coca-Cola Company invites consumers to download free songs on Music Monday, while supporting a campaign against AIDS. Based on the aforementioned evidence, we predict that consumers' perceived benefits are greater from this practice as it clearly indicates what types of benefits consumers will receive by contributing to the content. In addition, rewards given by companies more clearly indicate their efforts in contributing to consumers and/or society by spending their resources. Therefore, greater consumer benefits and firm efforts will lead to the perception that the firm has sincere motives to serve society rather than its own needs $[53,54]$. While the entertaining aspect in this practice may depend on context (e.g., the types of rewards), and therefore it is not clear whether such practice itself is entertaining or not, mentioning these types of rewards in branded messages will attract consumers' attention and increase interest by delivering clear messages about (positive) consequences. Therefore, it is predicted that rewarding consumers with CSR messages will increase consumer engagement.

Hypothesis 5 (H5). Rewarding consumers will increase consumer engagement with social media when used in CSR messages.

\subsection{The Number of Calls to Action}

We argue that the above five types of calls to action are not mutually exclusive because they are often used together within one message (e.g., inviting to a brand-related event and rewarding consumers for their participation). The next question explored in this research is whether using multiple calls to action within one (CSR) message increases engagement. Although there is no sufficient evidence in the current literature, this study posits that using more calls to action in CSR messages is less effective in driving user engagement. First, researchers have suggested that calls to action have negative outcomes such as decreases in overall enjoyment of the content [48] and user satisfaction [49] as consumers feel forced to contribute. It is predicted herein that these negative outcomes will be strengthened when more calls to action are used in a message because users feel more pressure while consuming it. It is also consistent with previous studies [53,54] in that more efforts are required by consumers within one message as the number of calls to action increases, while firms' efforts may decrease as they can create fewer messages to achieve the same amount 
of contribution. We predict that an increase in consumer efforts and a decrease in firms' efforts will lead to consumer skepticism toward CSR messages due to the perception that firms are not sincere in serving society [53-55].

Furthermore, CSR messages urging consumers to contribute to the content can be less effective in that users could become skeptical about the company's motives. It is also possible that firm-initiated participation could be effective when companies deliver clear messages to consumers about what can be achieved. However, if companies use several calls to action, the message is likely to be less clear about the actions they want consumers to take, leading to a decrease in effectiveness. Therefore, it is expected that more calls to action used in CSR messages will decrease consumer engagement.

Hypothesis 6 (H6). Using more calls to action within a CSR message will decrease consumer engagement with social media.

The theoretical framework on the effects of the types and number of calls to action in CSR messages on consumer engagement is presented in Figure 1. In order to test the above predictions, we discuss data and analysis results in the Methodology Section.

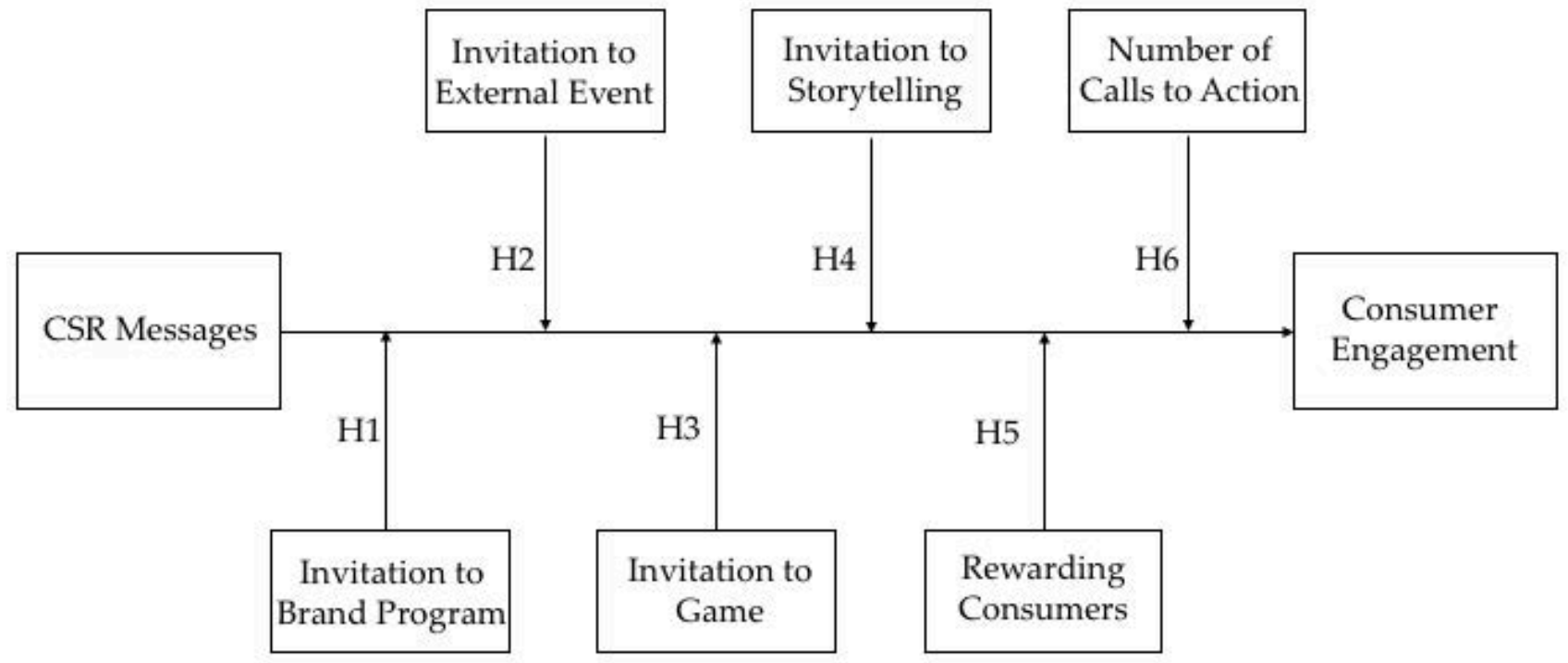

Figure 1. Proposed theoretical framework.

\section{Methodology}

\subsection{Data}

Analysis was performed on a collection of 2416 posts on their official social media accounts created from January 2015 to August 2015 by eight consumer product brands that are popular in the United States (i.e., Adidas, Allstate, Budweiser, Coca-Cola, Corona, McDonald's, Nike, and Red Bull), covering the sports, beverage, insurance, and fast-food industries. Branded posts uploaded by each firm on their official accounts on Facebook and Twitter were included in the analysis because these two platforms are the most actively used by firms for social media marketing and have the largest number of users. The dataset was completed by integrating information from several sources. First, we collected a list of branded posts with basic information such as engagement metrics or the time the posts were uploaded with the help of a social media agency. Second, our main study variables and other content characteristics for each post in the list were collected using an online consumer panel. Lastly, we extracted additional information such as text length, hashtag, or URLs using a search option within the text in the Excel datasheet. 


\subsubsection{Dependent Variables}

The literature defines consumer engagement as "the level of the customer's (or potential customer's) interactions and connections with the brand or firm's offerings or activities, often involving others in the social network created around the brand/offering/activity" [62]. Similarly, Saura et al. [63] have defined engagement as "interaction between the company and its on-line community" in the digital environment. Furthermore, Reyes-Menendez et al. [64] have highlighted the importance of engagement and argue that it is one of the key metrics to measure the efficiency of marketing strategies in the digital era. Scholars have also argued that engagement brings forth positive attitudes and viral outcomes such as shares, referrals, or comments [65], indicating that attitudinal and behavioral perspectives are considered in engagement $[66,67]$. In the context of social media, engagement metrics have been studied in terms of likes (i.e., favorites on Twitter) or shares (i.e., retweets on Twitter) [3,18-21]. In this study, the main dependent variables were the number of likes as an attitudinal engagement measure and the number of shares as a behavioral engagement measure, while the number of comments was also considered in additional analysis. We obtained the number of likes, shares, and comments on each post from a social media agency along with the list of brands and the links of their social media posts.

\subsubsection{Independent Variables}

We used the grounded theory approach [50] as a basis and classified our main study variables via two stages. First, in the open coding stage, we worked with two research assistants who were not familiar with the study context to review the dataset. During the process, we identified five common types of contributions that companies solicit from users and checked if they were collectively exhaustive.

Next, in the structural coding stage, we coded the posts in our dataset into the five categories from Amazon Mechanical Turk (Mturk) workers. Mturk is an online space where researchers can ask workers to complete designed tasks and provide monetary compensation. We recruited workers who live in the United States and are over the age of 18. In addition, we filtered out workers by their acceptance rate and recruited those who had a $95 \%$ or above acceptance rate for quality of responses. We provided them with detailed instructions and examples to show how to code the posts according to the five categories. Each worker coded messages based on a created coding instruction whereby 1 indicates if a message contains CSR-related issues and 0 if not. The five main study variables were also coded based on a coding instruction containing descriptions of (1) invitations to brand programs, (2) invitations to external events, (3) invitations to games, (4) invitations to storytelling, and (5) rewarding consumers; these five variables were coded as 1 if the post contains such information and 0 if not. Next, the total number of calls to action was collected by calculating the sum of the five variables, resulting in a range between 0 (i.e., no call to action was used) and 5 (i.e., all five calls to action were used). Each post was coded by three to five workers and the classification was determined using the majority rule. Following that, two research assistants reviewed the works and reached an agreement after discussing any unclear cases (i.e., reliability scores measured by intraclass correlation coefficients [68] ranged between 0.67 to 0.92 , which are within the acceptable range [69]). This manual coding method is commonly used by social media $[20,70,71]$ because it is effective in extracting information from a dataset considering the message context [70].

For validation, we found evidence in the literature and confirmed with industry examples to ensure that the types of calls to action classified in our research have also been used in practice. Examples of calls to action in our dataset are presented in Table 1. 
Table 1. Examples of calls to action in the dataset.

\begin{tabular}{|c|c|c|c|}
\hline Types & CSR Message & Text (Accessed on 15 March 2021) & Brand \\
\hline \multirow{2}{*}{$\begin{array}{l}\text { Invitation to Brand } \\
\text { Programs }\end{array}$} & Yes & $\begin{array}{l}\text { Coke's } 2014 \text { FIFA World Cup Anthem is on a campaign to reach } \\
\text { football fans in over } 175 \text { countries! Follow the song's journey as } \\
120 \text { artists in } 22 \text { languages create } 24 \text { local versions of "The } \\
\text { World Is Ours"-http:/ / CokeURL.com/GlobalAnthem }\end{array}$ & Coca-Cola \\
\hline & No & $\begin{array}{c}\text { Your ticket to The Nike Academy is coming soon. Will you be } \\
\text { the Most Wanted? Download the Nike Soccer app: } \\
\text { nike.com/soccerapp }\end{array}$ & Nike \\
\hline \multirow{2}{*}{$\begin{array}{l}\text { Invitation to External } \\
\text { Events }\end{array}$} & Yes & $\begin{array}{l}164 \text { nationalities in } 32 \text { countries began the World Run. Watch } \\
\text { the ones still running live: http:/ / win.gs / WFLLive }\end{array}$ & RedBull \\
\hline & No & $\begin{array}{l}\text { Are you \#allin for \#Messi? RT for your chance to \#win an } \\
\text { Argentina jersey or @brazuca signed by Leo! \#FinalCopa }\end{array}$ & Adidas \\
\hline \multirow[b]{2}{*}{ Invitation to Games } & Yes & $\begin{array}{l}\text { Get creative and show your \#ArtOfCan today. } \\
\text { http:/ / www.redbullartofcan.com }\end{array}$ & RedBull \\
\hline & No & $\begin{array}{l}\text { Who's all fired up for the NASCAR STP 500? Join our } \\
\text { \#SpeedTweets contest. Every race weekend, you'll have the } \\
\text { chance to win a go-kart race with Kevin Harvick and some } \\
\text { other great prizes: www.budweiser.com/SpeedTweets—-with } \\
\text { Yvonne Roga, Db Vernon, and Trey Adams. }\end{array}$ & Budweiser \\
\hline \multirow{2}{*}{ Invitation to Storytelling } & Yes & $\begin{array}{c}\text { Redefine your definition of self. @denitiaandsene } \\
\text { \#givesyouwings }\end{array}$ & RedBull \\
\hline & No & If \#Fanta can be \#Fantastic, what can @CocaCola be? & Coca-Cola \\
\hline \multirow[b]{2}{*}{ Rewarding Consumers } & Yes & $\begin{array}{l}\text { Ready to roll up your sleeves and save a beach? Follow } \\
\text { @TheBlueFlag and \#SaveTheBeach to get the latest on our beach } \\
\text { cleanup efforts! }\end{array}$ & Corona \\
\hline & No & $\begin{array}{c}\text { Celebrate summertime with bold rewards with Fuze Summer } \\
\text { Fridays! Enter one Fuze 12-pack code every Friday to get } \\
\text { Double Points and unlock access to a surprise discounted } \\
\text { reward! While supplies last. 6/6-7/25. } \\
\text { http:/ / CokeURL.com/y5mg9 }\end{array}$ & Coca-Cola \\
\hline
\end{tabular}

\subsubsection{Control Variables}

For the control variables, a literature review was undertaken to find other message factors that are also known to affect engagement with social media. First, content characteristics were considered by examining if a message contains monetary, informational, or emotional characteristics. Social media researchers have examined if messages are informational (i.e., uses an information-based or rational appeal to gain consumers' interests or attention) and/or emotional (i.e., uses an emotional appeal to gain consumers' interests or attention based on the presence or strength of emotions) because this is one of the key factors that drive engagement in social media $[3,18-20,58]$. In addition, monetary characteristics (i.e., whether the message provides information about monetary benefits) are considered as engagement in social media is largely determined by whether the message is trying to sell something (i.e., persuasion-oriented) and by types of information provided in the message (i.e., about the product or brand) $[3,19]$. These variables are also coded based on a content analysis approach using manual coding, following the extant literature [72]. Similar to the process used in collecting calls to action variables, an online panel recruited from Mturk read the coding instruction along with definitions of the variables, whereby 1 indicates if a message contains (1) informational appeal, (2) emotional appeal, and (3) monetary appeal, and 0 if not.

Next, considering the format of messages, information was included about pictures, videos, use of questions, hashtags, URL, and length of text within the posts and incorporated into the model based on prior literature $[3,19,73]$. Information about hashtags, URLs, 
and length of text was extracted by researchers within the Excel datasheet using search and count functions. In addition, data provided by the agency containing topics within the messages, in terms of the use of people, product information, and humor, were accounted for. Finally, the platform (i.e., Facebook or Twitter) was considered in the analysis. Detailed descriptions and statistics regarding the variables in the dataset are presented in Table 2. The correlation matrix of the variables is presented in Table 3.

Table 2. Variable descriptions and statistics.

\begin{tabular}{|c|c|c|c|c|}
\hline Variable & Source & Descriptions & Mean & SD \\
\hline Likes (Favorites) & Agency & The number of likes (or favorites) the message received & 2552.23 & $11,998.63$ \\
\hline Shares (Retweets) & Agency & $\begin{array}{l}\text { The number of shares (or retweets) the message } \\
\text { received }\end{array}$ & 530.87 & 2968.31 \\
\hline CSR message & Consumer & $\begin{array}{l}\text { The message provides information about the social } \\
\text { good/social responsibility of the product or brand } \\
(1=\text { yes } / 0=\text { no) }\end{array}$ & 0.16 & 0.37 \\
\hline $\begin{array}{l}\text { (1) Invitation to } \\
\text { Brand Programs }\end{array}$ & Consumer & $\begin{array}{l}\text { The message is inviting consumers to participate in a } \\
\text { brand program or event }(1=\text { yes } / 0=\text { no })\end{array}$ & 0.23 & 0.42 \\
\hline $\begin{array}{l}\text { (2) Invitation to } \\
\text { External Events }\end{array}$ & Consumer & $\begin{array}{l}\text { The message is inviting to participate in a current } \\
\text { external event }(1=\text { yes } / 0=\text { no })\end{array}$ & 0.52 & 0.50 \\
\hline $\begin{array}{l}\text { (3) Invitation to } \\
\text { Games }\end{array}$ & Consumer & $\begin{array}{l}\text { The message is inviting to consumers to play a game or } \\
\text { a contest }(1=\text { yes } / 0=\text { no })\end{array}$ & 0.12 & 0.33 \\
\hline $\begin{array}{l}\text { (4) Invitation to } \\
\text { Storytelling }\end{array}$ & Consumer & $\begin{array}{l}\text { The message is encouraging consumers to engage in } \\
\text { further conversations by asking questions or seeking } \\
\text { answers }(1=\text { yes } / 0=\text { no) }\end{array}$ & 0.22 & 0.41 \\
\hline $\begin{array}{l}\text { (5) Rewarding } \\
\text { Consumers }\end{array}$ & Consumer & $\begin{array}{l}\text { The message is seeking to give rewards to consumers } \\
\text { for participation }(1=\text { yes } / 0=\text { no })\end{array}$ & 0.08 & 0.27 \\
\hline $\begin{array}{l}\text { Number of Calls to } \\
\text { Actions }\end{array}$ & Text & The total number of calls to action used in the message & 1.16 & 1.05 \\
\hline Emotional & Consumer & $\begin{array}{l}\text { The message uses an emotional appeal to gain } \\
\text { consumer interest or attention }(1=\text { yes } / 0=\text { no })\end{array}$ & 0.57 & 0.50 \\
\hline Informational & Consumer & $\begin{array}{l}\text { The message is uses information-based } / \text { rational appeal } \\
\text { to gain consumer interest or attention }(1=\text { yes } / 0=\text { no })\end{array}$ & 0.28 & 0.45 \\
\hline Monetary & Consumer & $\begin{array}{l}\text { The message provides information about the monetary } \\
\text { benefits of the product such as reduced price or more } \\
\text { value for money }(1=\text { yes } / 0=\text { no) }\end{array}$ & 0.05 & 0.22 \\
\hline Humor & Agency & The message uses a humor $(1=$ yes $/ 0=$ no $)$ & 0.14 & 0.35 \\
\hline Length of Text & Text & The total number of characters within the message & 101.25 & 59.60 \\
\hline Hashtag & Text & The message contains a hashtag $(1=$ yes $/ 0=$ no $)$ & 0.56 & 0.50 \\
\hline Picture & Agency & The message contains a picture $(1=$ yes $/ 0=$ no $)$ & 0.75 & 0.43 \\
\hline People & Agency & $\begin{array}{l}\text { The message contains images of people } \\
(1=\text { yes } / 0=\text { no })\end{array}$ & 0.46 & 0.50 \\
\hline Product & Agency & $\begin{array}{l}\text { The message contains images or information of a } \\
\text { product }(1=\text { yes } / 0=\text { no })\end{array}$ & 0.38 & 0.49 \\
\hline Video & Agency & The message contains a video $(1=$ yes $/ 0=$ no $)$ & 0.15 & 0.36 \\
\hline Question & Agency & The message uses a question $(1=$ yes $/ 0=$ no $)$ & 0.16 & 0.37 \\
\hline URL & Text & The message contains a URL $(1=$ yes $/ 0=$ no $)$ & 0.38 & 0.49 \\
\hline Platform & Agency & $1=$ Twitter $/ 0=$ Facebook & 0.57 & 0.50 \\
\hline
\end{tabular}


Table 3. Correlation matrix.

\begin{tabular}{|c|c|c|c|c|c|c|c|c|c|c|c|c|c|c|c|c|c|c|c|c|c|c|}
\hline & 1 & 2 & 3 & 4 & 5 & 6 & 7 & 8 & 9 & 10 & 11 & 12 & 13 & 14 & 15 & 16 & 17 & 18 & 19 & 20 & 21 & 22 \\
\hline 1. Likes (Favorites) & 1.00 & - & - & - & - & - & - & - & - & - & - & - & - & - & - & - & - & - & - & - & - & - \\
\hline 2. Shares (Retweets) & 0.72 & 1.00 & - & - & - & - & - & - & - & - & - & - & - & - & - & - & - & - & - & - & - & - \\
\hline 3. CSR message & -0.02 & -0.01 & 1.00 & - & - & - & - & - & - & - & - & - & - & - & - & - & - & - & - & - & - & - \\
\hline 4. Invitation to Brand Programs & -0.03 & -0.04 & 0.10 & 1.00 & - & - & - & - & - & - & - & - & - & - & - & - & - & - & - & - & - & - \\
\hline 5. Invitation to External Events & 0.03 & 0.05 & 0.13 & 0.15 & 1.00 & - & - & - & - & - & - & - & - & - & - & - & - & - & - & - & - & - \\
\hline 6. Invitation to Games & -0.01 & 0.01 & 0.12 & 0.19 & -0.01 & 1.00 & - & - & - & - & - & - & - & - & - & - & - & - & - & - & - & - \\
\hline 7. Invitation to Storytelling & -0.05 & -0.05 & 0.19 & 0.08 & 0.18 & 0.02 & 1.00 & - & - & - & - & - & - & - & - & - & - & - & - & - & - & - \\
\hline 9. Number of Calls to Actions & -0.04 & -0.02 & 0.23 & 0.63 & 0.50 & 0.56 & 0.52 & 0.47 & 1.00 & - & - & - & - & - & - & - & - & - & - & - & - & - \\
\hline 10. Emotional & 0.08 & 0.08 & -0.01 & 0.03 & 0.11 & 0.01 & -0.03 & -0.11 & 0.01 & 1.00 & - & - & - & - & - & - & - & - & - & - & - & - \\
\hline 11. Informational & -0.05 & -0.07 & 0.05 & 0.07 & -0.08 & -0.01 & 0.00 & 0.01 & 0.00 & -0.42 & 1.00 & - & - & - & - & - & - & - & - & - & - & - \\
\hline 12. Monetary & -0.04 & -0.03 & 0.00 & 0.09 & 0.01 & 0.02 & -0.01 & 0.18 & 0.10 & -0.18 & 0.21 & 1.00 & - & - & - & - & - & - & - & - & - & - \\
\hline 13. Humor & 0.08 & 0.08 & -0.04 & -0.08 & -0.01 & -0.06 & 0.02 & -0.03 & -0.06 & 0.06 & -0.06 & -0.04 & 1.00 & - & - & - & - & - & - & - & - & - \\
\hline 14. Length of Text & -0.04 & -0.05 & 0.11 & 0.17 & -0.01 & 0.21 & 0.10 & 0.13 & 0.24 & -0.12 & 0.16 & 0.10 & -0.05 & 1.00 & - & - & - & - & - & - & - & - \\
\hline 15. Hashtag & -0.10 & 0.00 & 0.03 & -0.05 & -0.01 & 0.06 & -0.03 & 0.03 & 0.01 & -0.06 & -0.07 & -0.06 & 0.01 & -0.07 & 1.00 & - & - & - & - & - & - & - \\
\hline 16. Picture & 0.03 & -0.02 & -0.03 & 0.02 & -0.04 & -0.04 & -0.10 & -0.02 & -0.07 & 0.02 & 0.03 & 0.01 & -0.09 & -0.09 & -0.11 & 1.00 & - & - & - & - & - & - \\
\hline 18. Product & 0.04 & -0.01 & -0.09 & -0.08 & -0.10 & -0.13 & -0.11 & -0.02 & -0.17 & 0.03 & 0.05 & -0.01 & 0.07 & -0.08 & -0.05 & 0.19 & -0.07 & 1.00 & - & - & - & - \\
\hline 19. Video & 0.09 & 0.11 & 0.00 & 0.00 & 0.06 & 0.04 & 0.05 & -0.03 & 0.05 & 0.05 & -0.10 & -0.06 & 0.21 & 0.05 & -0.02 & -0.39 & 0.23 & -0.02 & 1.00 & - & - & - \\
\hline 20. Question & -0.06 & -0.05 & 0.00 & 0.05 & 0.03 & 0.04 & 0.25 & 0.01 & 0.15 & -0.09 & 0.13 & 0.05 & 0.03 & 0.12 & -0.05 & -0.02 & -0.08 & -0.07 & -0.03 & 1.00 & - & - \\
\hline 21. URL & 0.01 & 0.00 & 0.06 & 0.15 & 0.06 & 0.20 & 0.11 & 0.06 & 0.23 & -0.02 & 0.12 & 0.06 & -0.09 & 0.32 & -0.08 & -0.12 & 0.02 & -0.10 & 0.09 & 0.03 & 1.00 & - \\
\hline 22. Platform & -0.20 & -0.04 & 0.07 & -0.07 & -0.03 & 0.03 & 0.00 & 0.01 & -0.02 & 0.00 & -0.06 & -0.01 & -0.04 & -0.15 & 0.39 & -0.19 & -0.01 & -0.14 & -0.13 & -0.10 & 0.13 & 1.00 \\
\hline
\end{tabular}




\subsection{Empirical Considerations}

Several empirical concerns arose from the nature of the data. First, the main dependent variables (i.e., likes and shares) are count variables with overdispersion; therefore, this study adopted a negative binomial regression model, following the previous studies on social media [20]. In addition, Vuong test results indicated that negative binomial regression would be more appropriate than zero-inflated negative binomial ( $p=1.000$ for likes; $p=0.9321$ for shares).

Second, the engagement level with previous posts is likely to affect engagement with the next post because each brand has a similar communication style across posts, and consumers' reactions to prior posts are also considered when designing subsequent posts. To account for this concern, lagged-dependent variables are included as control variables in the model.

Moreover, it is plausible to assume that brands have their own communication styles, fan bases, and marketing capabilities. Therefore, brand fixed effects are incorporated in the model to account for different characteristics across brands.

Finally, timing is also an important factor to consider when uploading posts. Thus, the month and day of the week when the post was uploaded are also included in the model.

\subsection{Results}

Before discussing the main analysis results, Table 4 provides an overview of the dataset, which presents the use of calls to action in CSR and non-CSR messages. The results show that among all CSR messages in the dataset, $32.64 \%$ use invitations to brand programs, $65.54 \%$ employ invitations to external events, $21.50 \%$ utilize games, $39.12 \%$ apply invitations to storytelling, and $13.21 \%$ use consumer rewards, indicating higher percentages than those of non-CSR messages across all five calls to action. In terms of the number of calls to action, close to $60 \%$ of CSR messages use one or two, while more than $60 \%$ of the non-CSR messages contain no or one call to action. Overall, the results indicate that CSR messages use calls to action more actively within the content than non-CSR messages.

Table 4. Use of calls to action in corporate social responsibility (CSR) vs. non-CSR messages.

\begin{tabular}{|c|c|c|c|c|c|}
\hline & & $\begin{array}{l}\text { Non-CSR } \\
\text { Messages }\end{array}$ & $\begin{array}{c}\% \text { in Total Non-CSR } \\
\text { Messages }\end{array}$ & CSR Messages & $\begin{array}{c}\% \text { in Total CSR } \\
\text { Messages }\end{array}$ \\
\hline \multirow{5}{*}{ Types of Calls to Action } & (1) Invitation to Brand Programs & 436 & 21.73 & 126 & 32.64 \\
\hline & (2) Invitation to External Events & 994 & 49.55 & 253 & 65.54 \\
\hline & (3) Invitation to Games & 208 & 10.37 & 83 & 21.50 \\
\hline & (4) Invitation to Storytelling & 368 & 18.34 & 151 & 39.12 \\
\hline & (5) Rewarding Consumers & 136 & 6.78 & 51 & 13.21 \\
\hline \multirow{6}{*}{$\begin{array}{l}\text { Number of Calls to } \\
\text { Action within a Message }\end{array}$} & 0 & 669 & 33.35 & 46 & 11.92 \\
\hline & 1 & 761 & 37.94 & 133 & 34.46 \\
\hline & 2 & 388 & 19.34 & 124 & 32.12 \\
\hline & 3 & 154 & 7.68 & 51 & 13.21 \\
\hline & 4 & 27 & 1.35 & 30 & 7.77 \\
\hline & 5 & 7 & 0.35 & 2 & 0.52 \\
\hline
\end{tabular}

3.3.1. Impact of Different Types of Calls to Action in CSR Messages on Likes and Shares

The main analysis results are presented in Table 5. First, a likelihood-ratio test of all regressions in our analysis resulted in a $p$-value less than 0.001 , showing that the model fit is statistically significant. The results show that CSR messages have a positive effect on likes $(\beta=0.40, \mathrm{SE}=0.23, p=0.089)$ and shares $(\beta=47, \mathrm{SE}=0.27, p=0.078)$, indicating that when messages discuss CSR issues, it results in higher levels of engagement. Next, different types of calls to action show mixed results about their effects on engagement. Invitations 
to brand programs have a negative effect on likes $(\beta=-0.25$, SE $=0.10, p=0.014)$ and shares $(\beta=-0.47, \mathrm{SE}=0.11, p<0.001)$. Rewarding consumers has a positive effect on likes ( $\beta=0.38, \mathrm{SE}=0.22, p=0.079)$, and invitations to external events have a positive effect on shares $(\beta=0.18, \mathrm{SE}=0.11, p=0.088)$. Other variables do not have significant influences on engagement outcomes. The results suggest that the effects of calls to action may vary depending on the way they are used.

Table 5. Effects of types of calls to action in CSR messages on likes and shares.

\begin{tabular}{|c|c|c|c|c|c|c|}
\hline & \multicolumn{3}{|c|}{ Likes } & \multicolumn{3}{|c|}{ Shares } \\
\hline & Coeff & SE & & Coeff & SE & \\
\hline Lag of DV & 0.000 & 0.000 & $* *$ & 0.000 & 0.000 & $* *$ \\
\hline CSR message & 0.398 & 0.234 & * & 0.471 & 0.267 & * \\
\hline Invitation to Brand Programs & -0.247 & 0.100 & $* *$ & -0.475 & 0.110 & $* * *$ \\
\hline Invitation to External Events & 0.123 & 0.090 & & 0.182 & 0.107 & * \\
\hline Invitation to Games & -0.067 & 0.145 & & -0.075 & 0.186 & \\
\hline Invitation to Storytelling & 0.030 & 0.112 & & 0.177 & 0.134 & \\
\hline Rewarding Consumers & 0.378 & 0.215 & * & 0.262 & 0.223 & \\
\hline $\begin{array}{c}\text { CSR message } \times \text { Invitation to Brand } \\
\text { Programs }\end{array}$ & 0.463 & 0.267 & * & 1.117 & 0.287 & $* * *$ \\
\hline $\begin{array}{c}\text { CSR message } \times \text { Invitation to } \\
\text { External Events }\end{array}$ & -0.074 & 0.226 & & -0.302 & 0.249 & \\
\hline CSR message $\times$ Invitation to Games & 1.265 & 0.475 & $* * *$ & 1.751 & 0.579 & $* * *$ \\
\hline $\begin{array}{l}\text { CSR message } \times \text { Invitation to } \\
\text { Storytelling }\end{array}$ & -0.924 & 0.265 & $* * *$ & -1.490 & 0.290 & $* * *$ \\
\hline $\begin{array}{l}\text { CSR message } \times \text { Rewarding } \\
\text { Consumers }\end{array}$ & -1.255 & 0.410 & $* * *$ & -1.197 & 0.417 & $* * *$ \\
\hline Emotional & -0.112 & 0.106 & & -0.080 & 0.124 & \\
\hline Informational & -0.186 & 0.105 & * & -0.187 & 0.120 & \\
\hline Monetary & -0.246 & 0.177 & & -0.259 & 0.195 & \\
\hline Humor & 0.429 & 0.118 & $* * *$ & 0.584 & 0.148 & $* * *$ \\
\hline Length of Text & -0.002 & 0.001 & $* * *$ & -0.003 & 0.001 & $* * *$ \\
\hline Hashtag & 0.323 & 0.079 & $* * *$ & 0.286 & 0.102 & $* * *$ \\
\hline Picture & 0.349 & 0.123 & $* * *$ & 0.388 & 0.140 & $* * *$ \\
\hline People & 0.115 & 0.085 & & 0.045 & 0.103 & \\
\hline Product & 0.254 & 0.089 & $* * *$ & 0.132 & 0.106 & \\
\hline Video & 0.300 & 0.147 & $* *$ & 0.743 & 0.169 & $* * *$ \\
\hline Question & -0.010 & 0.096 & & -0.028 & 0.112 & \\
\hline URL & -0.495 & 0.088 & $* * *$ & -0.462 & 0.098 & $* * *$ \\
\hline Platform & -2.961 & 0.102 & $* * *$ & -0.745 & 0.138 & $* * *$ \\
\hline Brand Fixed Effects & & $\checkmark$ & & & $\checkmark$ & \\
\hline Month & & $\checkmark$ & & & $\checkmark$ & \\
\hline Day of Week & & $\checkmark$ & & & $\checkmark$ & \\
\hline Log (Pseudo) Likelihood & & $5,692.84$ & & & $14,317.40$ & \\
\hline Pseudo R-Square & & .0877 & & & 0.0597 & \\
\hline
\end{tabular}

Note: ${ }^{* *}, * *$, and ${ }^{*}$ indicates significant at $1 \%, 5 \%$, and $10 \%$ level of significance based on $p$-value. 
The interaction effects between calls to action and CSR messages on engagement are significantly positive or negative. First, the interaction effects of invitations to brand programs and CSR messages are significant and positive on likes $(\beta=0.46, \mathrm{SE}=0.27$, $p=0.083)$ and shares $(\beta=1.12, \mathrm{SE}=0.29, p<0.001)$, indicating that this call to action in CSR messages increases engagement and supporting H1. However, the interaction effects of invitations to external events and CSR messages on likes and shares are not significant ( $p>0.1$ for both), and therefore, H2 is not supported. Next, the interaction effects of invitations to games and CSR messages are significant and positive on both likes $(\beta=1.26$, $\mathrm{SE}=0.47, p=0.008)$ and shares $(\beta=1.75, \mathrm{SE}=0.58, p=0.002)$, showing that this specific call to action in CSR messages is effective in enhancing engagement and also providing support for $\mathrm{H} 3$. In addition, the interaction effects of invitations to storytelling and CSR messages are significant and negative on likes $(\beta=-0.92, \mathrm{SE}=0.26, p<0.001)$ and shares $(\beta=-1.49, \mathrm{SE}=0.29, p<0.001)$, confirming H4. Finally, the interaction effects of rewarding consumers and CSR messages are significant and negative on likes $(\beta=-1.25, \mathrm{SE}=0.41$, $p=0.002)$ and shares $(\beta=-1.20, \mathrm{SE}=0.42, p=0.004)$, indicating that consumer rewards in CSR messages decrease engagement. Therefore, H5 is not supported.

\subsubsection{Effects of Total Number of Calls to Action in CSR Messages on Likes and Shares}

Results from the analysis of the effects of the total number of calls to action within a CSR message on engagement outcomes are presented in Table 6. First, the main effects of CSR messages are positive on likes $(\beta=0.64, \mathrm{SE}=0.28, p=0.021)$ and shares $(\beta=0.75, \mathrm{SE}=0.34$, $p=0.027$ ), which is consistent with the previous analysis results. The main effects of the total number of calls to action on likes and shares are not significant ( $p>0.1$ for both). The interaction effect of the total number of calls to action and CSR messages on likes is significant and negative $(\beta=-0.19, \mathrm{SE}=0.11, p=0.07)$, indicating that the engagement level decreases when more calls to action are used together in one CSR message and confirming H6. However, the effect was not found on shares $(p>0.1)$, and thus, no support is provided for H6.

Table 6. Effects of the number of calls to action in CSR messages on likes and shares.

\begin{tabular}{|c|c|c|c|c|c|c|}
\hline & & Likes & & & Shares & \\
\hline & Coeff & SE & & Coeff & SE & \\
\hline Lag of DV & 0.000 & 0.000 & $* *$ & 0.000 & 0.000 & $* *$ \\
\hline CSR message & 0.644 & 0.279 & $* *$ & 0.746 & 0.337 & $* *$ \\
\hline Number of Calls to Action & 0.017 & 0.045 & & -0.011 & 0.050 & \\
\hline CSR message $\times$ Number of Calls to Action & -0.194 & 0.107 & * & -0.195 & 0.125 & \\
\hline Emotional & -0.104 & 0.112 & & -0.048 & 0.133 & \\
\hline Informational & -0.290 & 0.119 & $* *$ & -0.290 & 0.141 & $* *$ \\
\hline Monetary & -0.304 & 0.173 & * & -0.418 & 0.179 & $* *$ \\
\hline Humor & 0.418 & 0.124 & $* * *$ & 0.595 & 0.161 & $* * *$ \\
\hline Length of Text & -0.002 & 0.001 & $* * *$ & -0.003 & 0.001 & $* * *$ \\
\hline Hashtag & 0.347 & 0.085 & $* * *$ & 0.317 & 0.118 & $* * *$ \\
\hline Picture & 0.288 & 0.138 & $* *$ & 0.286 & 0.162 & * \\
\hline People & 0.120 & 0.094 & & 0.048 & 0.112 & \\
\hline Product & 0.197 & 0.094 & $* *$ & 0.049 & 0.115 & \\
\hline Video & 0.269 & 0.153 & * & 0.700 & 0.174 & $* * *$ \\
\hline Question & -0.019 & 0.103 & & 0.009 & 0.135 & \\
\hline URL & -0.456 & 0.091 & $* * *$ & -0.426 & 0.109 & $* * *$ \\
\hline Platform & -2.943 & 0.107 & $* * *$ & -0.721 & 0.149 & $* * *$ \\
\hline Brand Fixed Effects & & $\checkmark$ & & & $\checkmark$ & \\
\hline Month & & $\checkmark$ & & & $\checkmark$ & \\
\hline Day of Week & & $\checkmark$ & & & $\checkmark$ & \\
\hline Log (Pseudo) Likelihood & & $-16,741.16$ & & & $-14,394.05$ & \\
\hline Pseudo R-Square & & 0.0851 & & & 0.0547 & \\
\hline
\end{tabular}




\subsection{Robustness Check}

First, we tested the model using the number of comments as our dependent variable to examine if the effects hold across diverse engagement metrics. We found a positive and significant effect of invitation to brand programs $(\beta=0.60, \mathrm{SE}=0.36, p=0.096)$ and a negative and significant effect of rewarding consumers $(\beta=-1.35, \mathrm{SE}=0.51, p=0.007)$ on comments, which is consistent with the main study results. In line with the results on likes and shares, the invitation to external events also does not show a significant effect on comments $(p>0.1)$. However, the effects of invitation to games and invitation to storytelling on comments are also not significant $(p>0.1)$. Overall, the effects of calls to action are less pronounced on comments, compared to likes and shares, while overall directions remain consistent.

Second, to examine if outliers affect the study results, data were winsorized at $1 \%$ and $5 \%$ levels to test if the results remain consistent. The interaction effects of the five types of calls to action and CSR messages stay consistent for likes at both the $1 \%$ and $5 \%$ levels. The interaction effects of the calls to action and CSR messages are also consistent for shares at the $1 \%$ level. However, the effects of invitations to games and rewarding consumers in CSR messages become less significant on shares at the $5 \%$ level $(p>0.1)$, while the directions remain consistent. The interaction effect of the number of calls to action and CSR messages on likes also stay consistent at the $1 \%$ level.

\section{Discussion}

This research examined how different types of calls to action, which are widely used in social media, are more or less effective on consumer engagement when used in CSR messages. Five types of calls to action were categorized according to data, and not all are equally effective in enhancing engagement. The analysis results suggest that companies invitations to their campaigns or programs and games within CSR messages enhance both attitudinal and behavioral engagement outcomes, which are measured by likes and shares. These findings indicate that encouraging consumer participation must be more specific and relevant to brands by linking it to the company's own programs or campaigns (e.g., Dove's Real Beauty campaign) to attract user attention and deliver the message that the company is making real efforts to support the issues. The results are also in line with the previous findings that internal CSR messages (i.e., more directly relevant to firms) are more effective [31] and a clear fit between brand and message content leads to higher engagement [59], extending the findings into the domain of CSR communications in social media. In addition, entertaining aspects of messages are also important in CSR communications because they encourage consumers to participate and contribute to the content, driven by interest and enjoyment. The findings contribute to the extant literature by confirming the idea that social media messages must be entertaining [57,58], advancing our understanding of social media communications into CSR messages.

In contrast, inviting consumers to storytelling and engaging in further conversations is not effective in CSR messages, decreasing the level of likes and shares. The effects of this practice are shown to be consistent with this study's prediction and in line with the idea that more efforts required by consumers and fewer efforts made by firms hurt the message's effectiveness [53]. Similar findings are also shown in the related literature that consumers are more skeptical about firms' ability and perceive that a message was only persuasive when the message was created with greater consumer contribution compared to the firm's [61]. However, the findings do not show a significant interaction effect of invitations to external events with CSR messages on consumers' attitudinal and behavioral engagement. One of the possibilities explaining the insignificant effect would be that the nature of external events forms a weaker connection with CSR issues promoted by companies, thereby decreasing interest. Although this highlights the importance of a fit between brand and message content [59], it is also consistent with the previous findings on the effectiveness of CSR messages in that they should speak to issues directly relevant to firms in order to persuade stakeholders [31]. 
Perhaps the most surprising finding is that rewarding consumers in CSR messages is less effective in driving attitudinal and behavioral engagement, which is the opposite of the hypothesis. Although the underlying causes were not specifically studied in this research, several possible scenarios could help explain the negative effect. First, rewards stated in CSR messages might vary in their effectiveness depending on the type. For example, this study did not distinguish among rewards such as experiences, information, and monetary compensation and instead treated them the same in the analysis. It is possible that consumers would seek monetary compensation from CSR messages rather than other types of compensation. Alternatively, the rewards may vary by magnitude, amount, or relevance, but these considerations were also not included in the analysis.

Second, it is plausible that CSR communications differ from non-CSR communications, and consumers do not consider rewards to be an important driver of their contribution to the former. Therefore, it would be worthwhile to investigate the characteristics and types of customer rewards further to gain a better understanding of why and how they do not seem to work in CSR messages.

Third, although we predicted that the entertaining benefit in the practice of rewarding consumers is unclear and may depend on context, it is possible that CSR messages rewarding consumers in our dataset were not entertaining enough compared to the other practice, which resulted in lower levels of engagement $[57,58]$.

The number of calls to action matters in CSR communications. Consistent with the hypothesis, more calls to action used in CSR messages decreased consumers' attitudinal engagement. However, the effects become less significant on behavioral engagement, while the overall direction remains consistent. Although further analysis is suggested, this study posits that the effects are more pronounced on likes because it is easier to click a "like" button on the platforms compared to "shares," which require further steps to be taken. We also examined the effects of calls to action in CSR messages on "comments" and found the effects less pronounced compared to "likes" or "shares," while overall directions remain consistent. We posit that such a difference arose from the nature of engagement metrics. Scholars have found that the effects of social media messages are different on "comments," compared to "likes" or "shares" [57]. While scholars have mixed views on why and how the effects differ on the three metrics, Ji et al. [58] have argued that these differences arise from the varying degrees of engagement, in which "likes" is the shallowest level, and "comments" indicates the deepest level of engagement. Therefore, it is plausible that our effects are more pronounced on "likes" and "shares" because they are easier to implement compared to "comments." While it is also possible that the mechanisms differ on "comments," future studies would benefit from further exploring the differences among those engagement metrics and studying various strategies to target different metrics.

\subsection{Managerial Implications}

This research is among the first in literature that goes beyond a study of the overall effectiveness of calls to action on consumer engagement in social media and explores diverse types of calls to action along with their effectiveness when used in CSR messages. The findings of this research provide novel insights and actionable guidelines for managers in terms of how to better communicate CSR issues to consumers and encourage their contributions using social media.

This research suggests that not all calls to action are equally effective in CSR messages, and several types are shown to decrease engagement levels. Therefore, it is suggested that social media marketing managers use calls to action strategically, considering how they could deliver sincere motives of serving society and entertain consumers at the same time.

Findings in this research suggest the following implications to managers. First, managers must consider a fit between brand and message content and are encouraged to utilize items that are more specific and relevant to their companies and develop programs accordingly. More specifically, firms are encouraged to develop their own programs or events that are more appropriate to brand characteristics to promote relevant societal issues. For exam- 
ple, the Save Our Species campaign designed by Lacoste provides a clear understanding of why the brand aims to protect nature and wildlife, based on the fit between the message and brand. While firms may also utilize external events or moments in their CSR messages to attract consumers' attention, we suggest that firms make a clear connection between the events and brand characteristics to demonstrate the reasons they are promoting these events and their sincere motives to promote values benefiting society. For example, external sporting events such as the Olympics or World Cup offer firms an opportunity to promote relevant societal topics (e.g., world peace, freedom from bias, overcoming challenges). However, it is possible that many firms end up delivering the same message to consumers, which undermines persuasiveness and decreases engagement with the message because such events also serve as an opportunity for other firms. Therefore, firms must ensure that brand-specific items are incorporated into messages (e.g., creating brand songs, introducing brand ambassadors, or creating their own events related to the external events) to make sense of why they are promoting specific societal issues using those events.

Second, they should also include entertaining aspects such as games or contests in CSR messages to make consumers interested in the issues and want to voluntarily participate. Previous studies $[57,58]$ and our study findings have shown that entertaining consumers is a must in driving engagement in social media. Using the interactive nature of the platform, firms have an opportunity to adopt diverse tactics to attract consumers' attention and ensure that they have fun during participation. Therefore, we suggest firms adopt quizzes, contests, or other types of games in CSR messages because the challenging aspects of these tactics drive participation and make consumers anticipate and curious about the results, leading them to enjoy the content during the process. We expect that consumers' enjoyment in CSR messages will lead to greater interests in the issues that firms aim to promote.

Moreover, this research suggests that calls to action must be used with caution because multiple calls to action do not lead to higher levels of engagement. Indeed, this study argues that the use of diverse calls to action within a message could decrease the clarity of the goals and increase pressure on consumers, which could reduce their overall enjoyment of the content. Therefore, managers are recommended to focus on one or two of the most important actions required of consumers and clearly deliver them in the message.

\subsection{Limitations and Future Research Directions}

Suggestions for future research directions are based on several limitations in this study. First, this research is an exploratory analysis studying the five types of calls to action based on the dataset and examples in practice. Future studies could contribute to the literature by further investigating types of calls to action based on theoretical grounds and proving an overarching framework of calls to action.

Secondly, although the dataset consists of several popular brands, it is limited to US companies and was collected several years ago. It is possible that more recent social media practices from other countries show different dynamics. Thus, to achieve more robust results that are generalizable across time and contexts, analysis based on more recent data from different brands across various countries is suggested as a future research direction.

Thirdly, although the empirical study findings show that different types of calls to action affect consumer engagement outcomes on social media, the mechanisms by which those variables are related to engagement are not illustrated in this research. Future studies could advance this understanding of CSR communications on social media and find ways to strengthen the positive effects of calls to action by taking an additional step to explore the mechanisms by which different types and numbers of calls to action affect consumers attitudinal and behavioral engagement outcomes. Moreover, future studies could take additional steps to extract topics and sentiments in consumers' comments and provide more valuable insights into literature since more users can express their opinions through social media [73].

Finally, since many firms utilize external events or moments and incorporate them into social media messages to attract users, it is likely that there are special times within 
a year (e.g., Valentine's Day or Christmas) that systematically affect firms' strategies and users' attention and interests, thereby impacting our study results. While information regarding those times and characteristics is beyond the scope of our dataset and study, future research could take one step further and explore the effects of special events and times on CSR messaging and consumer engagement.

\section{Conclusions}

Social media is now more of an essential than an optional component for companies for marketing practice and communications with consumers. Although much attention in the literature has been paid to enhancing marketing effectiveness and developing business capabilities using this platform, our research proposes ways that companies could contribute to sustainable development at the same time, leading to a "win-win" scenario. In particular, we suggest more specific and actionable guidelines to companies by promoting CSR-related activities and information to consumers by leveraging diverse types of calls to action in their branded messages in social media. Based on analysis of a set of branded posts on Facebook and Twitter, this study suggests that firms promote calls to action that are more directly relevant and specific to their brands, rather than external events, for more effective CSR communications, given that invitations to brand programs in CSR messages showed a positive impact on engagement, while invitations to external events did not show a significant impact. In addition, firms must also ensure that their calls to action in CSR messages are entertaining to consumers because this is the key aspect in driving engagement in social media, as evidenced by the positive impact on engagement metrics of invitation to games and the negative impact of invitation to storytelling in CSR messages. Finally, firms must use calls to action with caution and try not to utilize many items within one CSR message.

By understanding and utilizing the effects of diverse calls to action in CSR messages, companies could enhance consumers' attitudinal and behavioral engagement in social media, followed by enhanced business capabilities and firm performance. At the same time, these practices contribute to the sustainable development goals (SDGs) for both the society and the companies themselves through consumers' more active learning and participation in activities related to long-term development.

Funding: This research received no external funding.

Institutional Review Board Statement: Ethical review and approval were waived for this study, because questions during the information-gathering process focused on objects or products rather than the subjects (i.e., personal information about the individuals) and no identifiable private information was collected, following the ethical guidelines and definitions of "studies that are not human subjects research".

Informed Consent Statement: Not applicable.

Data Availability Statement: The data presented in this study are available on request from the corresponding author.

Conflicts of Interest: The author declares no conflict of interest.

\section{References}

1. Ashley, C.; Tuten, T. Creative strategies in social media marketing: An exploratory study of branded social content and consumer engagement. Psychol. Mark. 2015, 32, 15-27. [CrossRef]

2. Uzunoğlu, E.; Türkel, S.; Akyar, B.Y. Engaging consumers through corporate social responsibility messages on social media: An experimental study. Public Relat. Rev. 2017, 43, 989-997. [CrossRef]

3. Stephen, A.T.; Sciandra, M.R.; Inman, J.J. The Effects of Content Characteristics on Consumer Engagement with Branded Social Media Content on Facebook. 2015. Available online: https://www.msi.org/wp-content/uploads/2020/06/MSI_Report_15-1101. pdf (accessed on 15 February 2021).

4. Small Business Trends. Are 87 Percent of Small Businesses Using Social Media Wrong? Available online: https://smallbiztrends. com/2012/09/vocus-social-media-survey.html (accessed on 15 February 2021). 
5. Linkedin Business Solutions. IT Purchase Goes Social. 2012. Available online: https://business.linkedin.com/content/ dam/business/marketing-solutions/global/en_US/site/pdf/wp/linkedin-marketing-solutions-itdm.pdf (accessed on 15 February 2021).

6. Ballew, M.T.; Omoto, A.M.; Winter, P.L. Using Web 2.0 and social media technologies to foster proenvironmental action. Sustainability 2015, 7, 10620-10648. [CrossRef]

7. Cone Communications 2010. 2010 Cause Evolution Study. Available online: https://www.conecomm.com/research-blog/2010 -cause-evolution-study (accessed on 15 February 2021).

8. Sutton, J. Why Social Media and Sustainability Should Go Hand in Hand. 2016. Available online: http:/ / www.triplepundit.com/ 2016/06/social-media-sustainability-go-hand-hand/ (accessed on 15 February 2021).

9. Zavy. 3 Social Campaigns that Nailed CSR and Made a Difference. 2019. Available online: https://www.zavy.co/blog/3-socialcampaigns-that-nailed-csr-and-made-a-difference (accessed on 15 February 2021).

10. Du, S.; Bhattacharya, C.B.; Sen, S. Reaping relational rewards from corporate social responsibility: The role of competitive positioning. Int. J. Res. Mark. 2007, 24, 224-241. [CrossRef]

11. Pava, M.L.; Krausz, J. The association between corporate social-responsibility and financial performance: The paradox of social cost. J. Bus. Ethics 1996, 15, 321-357. [CrossRef]

12. Dunn, K.; Harness, D. Communicating corporate social responsibility in a social world: The effects of company-generated and user-generated social media content on CSR attributions and scepticism. J. Mark. Manag. 2018, 34, 1503-1529. [CrossRef]

13. Du, S.; Bhattacharya, C.B.; Sen, S. Maximizing business returns to corporate social responsibility (CSR): The role of CSR communication. Int. J. Manag. Rev. 2010, 12, 8-19. [CrossRef]

14. Zalmanson, L.; Oestreicher-Singer, G. Your Action is Needed': The Effect of Website-Initiated Participation on User Contributions to Content Websites. 2015. Available online: https://www.msi.org/wp-content/uploads/2020/06/MSI_Report_15-118.pdf (accessed on 15 February 2021).

15. Whelan, G.; Moon, J.; Grant, B. Corporations and citizenship arenas in the age of social media. J. Bus. Ethics 2013, 118, 777-790. [CrossRef]

16. Fernandes, T.; Remelhe, P. How to engage customers in co-creation: Customers' motivations for collaborative innovation. J. Strateg. Mark. 2016, 24, 311-326. [CrossRef]

17. Gambetti, R.C.; Graffigna, G. The concept of engagement: A systematic analysis of the ongoing marketing debate. Int. J. Mark. Res. 2010, 52, 801-826. [CrossRef]

18. De Vries, L.; Gensler, S.; Leeflang, P.S. Popularity of brand posts on brand fan pages: An investigation of the effects of social media marketing. J. Interact. Mark. 2012, 26, 83-91. [CrossRef]

19. Lee, D.; Hosanagar, K.; Nair, H.S. Advertising content and consumer engagement on social media: Evidence from Facebook. Manag. Sci. 2018, 64, 5105-5131. [CrossRef]

20. Yang, M.; Ren, Y.; Adomavicius, G. Understanding user-generated content and customer engagement on Facebook business pages. Inf. Syst. Res. 2019, 30, 839-855. [CrossRef]

21. Akpinar, E.; Berger, J. Valuable virality. J. Mark. Res. 2017, 54, 318-330. [CrossRef]

22. Kent, M.L.; Taylor, M. From Homo Economicus to Homo dialogicus: Rethinking social media use in CSR communication. Public Relat. Rev. 2016, 42, 60-67. [CrossRef]

23. Rim, H.; Song, D. The ability of corporate blog communication to enhance CSR effectiveness: The role of prior company reputation and blog responsiveness. Int. J. Strateg. Commun. 2013, 7, 165-185. [CrossRef]

24. Reyes-Menendez, A.; Saura, J.R.; Filipe, F. Marketing challenges in the \#MeToo era: Gaining business insights using an exploratory sentiment analysis. Heliyon 2020, 6, e03626. [CrossRef] [PubMed]

25. Cho, M.; Furey, L.D.; Mohr, T. Communicating corporate social responsibility on social media: Strategies, stakeholders, and public engagement on corporate Facebook. Bus. Prof. Commun. Q. 2017, 80, 52-69. [CrossRef]

26. Galati, A.; Sakka, G.; Crescimanno, M.; Tulone, A.; Fiore, M. What is the role of social media in several overtones of CSR communication? The case of the wine industry in the Southern Italian regions. Br. Food J. 2019. [CrossRef]

27. Chu, S.C.; Chen, H.T.; Gan, C. Consumers' engagement with corporate social responsibility (CSR) communication in social media: Evidence from China and the United States. J. Bus. Res. 2020, 110, 260-271. [CrossRef]

28. Du, S.; Vieira, E.T. Striving for legitimacy through corporate social responsibility: Insights from oil companies. J. Bus. Ethics 2012, 110, 413-427. [CrossRef]

29. Lee, H.H.M.; Van Dolen, W.; Kolk, A. On the role of social media in the 'responsible' food business: Blogger buzz on health and obesity issues. J. Bus. Ethics 2013, 118, 695-707. [CrossRef]

30. Sen, S.; Bhattacharya, C.B.; Korschun, D. The role of corporate social responsibility in strengthening multiple stakeholder relationships: A field experiment. J. Acad. Mark. Sci. 2006, 34, 158-166. [CrossRef]

31. Wang, R.; Huang, Y. Communicating corporate social responsibility (CSR) on social media. Corp. Commun. Int. J. 2018. [CrossRef]

32. Sreejesh, S.; Sarkar, J.G.; Sarkar, A. CSR through social media: Examining the intervening factors. Mark. Intell. Plan. 2019, 38, 103-119. [CrossRef]

33. Zizka, L. The (mis) use of social media to communicate CSR in hospitality. J. Hosp. Tour. Technol. 2017, 8, 73-86. [CrossRef]

34. Parmelee, J.H.; Bichard, S.L. Politics and the Twitter Revolution: How Tweets Influence the Relationship between Political Leaders and the Public; Lexington Books: Plymourh, UK, 2011. 
35. Khajeheian, D.; Ebrahimi, P. Media branding and value co-creation: Effect of user participation in social media of news media on attitudinal and behavioural loyalty. Eur. J. Int. Manag. 2020, 14, 254-273.

36. Kamboj, S.; Rahman, Z. The influence of user participation in social media-based brand communities on brand loyalty: Age and gender as moderators. J. Brand Manag. 2016, 23, 679-700. [CrossRef]

37. Bründl, S. Passive, Active, or Co-Active? The Link Between Synchronous User Participation and Willingness to Pay for Premium Options. In Proceedings of the 51st Hawaii International Conference on System Sciences, Hilton Waikoloa Village, HI, USA, 3-6 January 2018. [CrossRef]

38. Festinger, L. A Theory of Cognitive Dissonance; Stanford University Press: Stanford, CA, USA, 1957; Volume 2.

39. Hsee, C.K.; Yang, A.X.; Wang, L. Idleness aversion and the need for justifiable busyness. Psychol. Sci. 2010, 21, 926-930. [CrossRef]

40. Ilany Tzur, N.; Zalmanson, L.; Oestreicher-Singer, G. The Dark Side of User Participation-The Effect of Calls to Action on Trust and Information Revelation. 2016. Available online: https:/ / ssrn.com/abstract=2814903 (accessed on 15 February 2021).

41. Drenner, S.; Sen, S.; Terveen, L. Crafting the initial user experience to achieve community goals. In Proceedings of the 2008 ACM Conference on Recommender Systems, Lausanne, Switzerland, 23-25 October 2008; pp. 187-194. [CrossRef]

42. Chen, T.Y.; Yeh, T.L.; Chang, C.I. How different advertising formats and calls to action on videos affect advertising recognition and consequent behaviours. Serv. Ind. J. 2020, 40, 358-379. [CrossRef]

43. Zalmanson, L.; Oestreicher-Singer, G.; Perez, D. Please Rate Your Experience-The Effect of Calls to Action on Website User Conversion. 2017. Available online: http:/ / dx.doi.org/10.2139/ssrn.3044779 (accessed on 15 February 2021).

44. Liliqust, M. What Is a Call to Action? The Balance Small Business. 2020. Available online: https://www.thebalancesmb.com/callto-action-1794380 (accessed on 18 March 2021).

45. Cohen, H. How to Improve Your Social Media Calls to Action. Social Media Examiner. 2013. Available online: https: / / www.socialmediaexaminer.com/how-to-improve-your-social-media-calls-to-action/\#: \{\}:text=A \% 20call\%20to \% 20action\%20is,you\%20want \%20them\%20to\%20take (accessed on 18 March 2021).

46. TrackMaven. The Marketing Maven's Guide to Facebook. 2014. Available online: http://pages.trackmaven.com/rs/251-LXF-77 8/images/TrackMaven_Facebook_Report_2014.pdf (accessed on 15 February 2021).

47. Sharma, L. 5 Ways to Encourage User Generated Content on Social Media. Social Media Today. 2017. Available online: https://www.socialmediatoday.com/social-business/5-ways-encourage-user-generated-content-social-media (accessed on 15 February 2021).

48. Handayani, R.C.; Purwandari, B.; Solichah, I.; Prima, P. The Impact of Instagram “Call-to-Action" Buttons on Customers' Impulse Buying. In Proceedings of the 2nd International Conference on Business and Information Management, Barcelona, Spain, 20-22 September 2018; pp. 50-56. [CrossRef]

49. Edwards, S.M.; Li, H.; Lee, J.H. Forced exposure and psychological reactance: Antecedents and consequences of the perceived intrusiveness of pop-up ads. J. Advert. 2002, 31, 83-95. [CrossRef]

50. Glaser, B.G.; Strauss, A.L.; Strutzel, E. The discovery of grounded theory; strategies for qualitative research. Nurs. Res. 1968, 17, 364. [CrossRef]

51. Ellen, P.S.; Webb, D.J.; Mohr, L.A. Building corporate associations: Consumer attributions for corporate socially responsible programs. J. Acad. Mark. Sci. 2006, 34, 147-157. [CrossRef]

52. Öberseder, M.; Schlegelmilch, B.B.; Gruber, V. "Why don't consumers care about CSR?": A qualitative study exploring the role of CSR in consumption decisions. J. Bus. Ethics 2011, 104, 449-460. [CrossRef]

53. Campbell, M.C. When attention-getting advertising tactics elicit consumer inferences of manipulative intent: The importance of balancing benefits and investments. J. Consum. Psychol. 1995, 4, 225-254. [CrossRef]

54. Yoon, Y.; Gürhan-Canli, Z.; Schwarz, N. The effect of corporate social responsibility (CSR) activities on companies with bad reputations. J. Consum. Psychol. 2006, 16, 377-390. [CrossRef]

55. Modig, E.; Dahlén, M.; Colliander, J. Consumer-perceived signals of 'creative' versus 'efficient' advertising: Investigating the roles of expense and effort. Int. J. Advert. 2014, 33, 137-154. [CrossRef]

56. Adams, J.S. Inequity in social exchange. In Advances in Experimental Social Psychology; Academic Press: Cambridge, MA, USA, 1965; Volume 2, pp. 267-299.

57. Menon, R.V.; Sigurdsson, V.; Larsen, N.M.; Fagerstrøm, A.; Sørensen, H.; Marteinsdottir, H.G.; Foxall, G.R. How to grow brand post engagement on Facebook and Twitter for airlines? An empirical investigation of design and content factors. J. Air Transp. Manag. 2019, 79, 101678. [CrossRef]

58. Ji, Y.G.; Chen, Z.F.; Tao, W.; Li, Z.C. Functional and emotional traits of corporate social media message strategies: Behavioral insights from S \& P 500 Facebook data. Public Relat. Rev. 2019, 45, 88-103. [CrossRef]

59. Lee, H.S.; Cho, C.H. The matching effect of brand and sporting event personality: Sponsorship implications. J. Sport Manag. 2009, 23, 41-64. [CrossRef]

60. Berger, A.; Schlager, T.; Sprott, D.E.; Herrmann, A. Gamified interactions: Whether, when, and how games facilitate self-brand connections. J. Acad. Mark. Sci. 2018, 46, 652-673. [CrossRef]

61. Thompson, D.V.; Malaviya, P. Consumer-generated ads: Does awareness of advertising co-creation help or hurt persuasion? J. Mark. 2013, 77, 33-47. [CrossRef]

62. Vivek, S.D.; Beatty, S.E.; Dalela, V.; Morgan, R.M. A generalized multidimensional scale for measuring customer engagement. J. Mark. Theory Pract. 2014, 22, 401-420. [CrossRef] 
63. Saura, J.R.; Palos-Sánchez, P.; Cerdá Suárez, L.M. Understanding the digital marketing environment with KPIs and web analytics. Future Internet 2017, 9, 76. [CrossRef]

64. Reyes-Menendez, A.; Saura, J.R.; Palos-Sanchez, P. Identifying key performance indicators for marketing strategies in mobile applications: A systematic literature review. Int. J. Electron. Mark. Retail. 2020, 11, 259-277. [CrossRef]

65. Brodie, R.J.; Hollebeek, L.D.; Jurić, B.; Ilić, A. Customer engagement: Conceptual domain, fundamental propositions, and implications for research. J. Serv. Res. 2011, 14, 252-271. [CrossRef]

66. Celebi, S.I. How do motives affect attitudes and behaviors toward internet advertising and Facebook advertising? Comput. Hum. Behav. 2015, 51, 312-324. [CrossRef]

67. An, S.; Kerr, G.; Jin, H.S. Recognizing native ads as advertising: Attitudinal and behavioral consequences. J. Consum. Aff. 2019, 53, 1421-1442. [CrossRef]

68. Shrout, P.E.; Fleiss, J.L. Intraclass correlations: Uses in assessing rater reliability. Psychol. Bull. 1979, 86, 420-428. [CrossRef]

69. Koo, T.K.; Li, M.Y. A guideline of selecting and reporting intraclass correlation coefficients for reliability research. J. Chiropr. Med. 2016, 15, 155-163. [CrossRef]

70. Loo, P.T. Exploring airline Companies' engagement with their passengers through social network: An investigation from their Facebook pages. Tour. Manag. Perspect. 2020, 34, 100657. [CrossRef]

71. Cvijikj, I.P.; Michahelles, F. Online engagement factors on Facebook brand pages. Soc. Netw. Anal. Min. 2013, 3, 843-861. [CrossRef]

72. Luarn, P.; Lin, Y.F.; Chiu, Y.P. Influence of Facebook brand-page posts on online engagement. Online Inf. Rev. 2015, 29, 505-519. [CrossRef]

73. Reyes-Menendez, A.; Saura, J.R.; Alvarez-Alonso, C. Understanding \#WorldEnvironmentDay user opinions in Twitter: A topicbased sentiment analysis approach. Int. J. Environ. Res. Public Health 2018, 15, 2537. [CrossRef] 